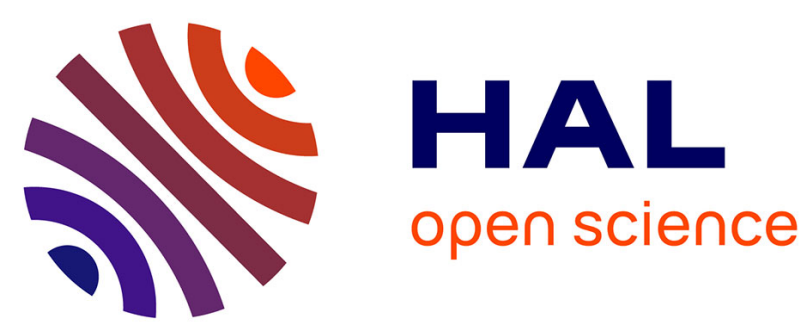

\title{
Dynamic recovery policies for time-critical supply chains under conditions of ripple effect
}

Dmitry Ivanov, Boris Sokolov, Inna Solovyeva, Alexandre Dolgui, Ferry Jie

\section{To cite this version:}

Dmitry Ivanov, Boris Sokolov, Inna Solovyeva, Alexandre Dolgui, Ferry Jie. Dynamic recovery policies for time-critical supply chains under conditions of ripple effect. International Journal of Production Research, 2016, 54 (23), pp.7245 - 7258. 10.1080/00207543.2016.1161253 . hal-01313033

\section{HAL Id: hal-01313033 \\ https://hal.science/hal-01313033}

Submitted on 12 May 2017

HAL is a multi-disciplinary open access archive for the deposit and dissemination of scientific research documents, whether they are published or not. The documents may come from teaching and research institutions in France or abroad, or from public or private research centers.
L'archive ouverte pluridisciplinaire HAL, est destinée au dépôt et à la diffusion de documents scientifiques de niveau recherche, publiés ou non, émanant des établissements d'enseignement et de recherche français ou étrangers, des laboratoires publics ou privés. 
This is an Author's Original Manuscript of an article published by Taylor \& Francis in International Journal of Production Research on 13.03.2016, available online: $\underline{\text { http://www.tandfonline.com/ }}$ /http://dx.doi.org/10.1080/00207543.2016.1161253]."

\title{
Dynamic Recovery Policies for Time-Critical Supply Chains under Conditions of Ripple Effect
}

\author{
Dmitry Ivanov $^{1}$, Boris Sokolov ${ }^{2,6}$, Inna Solovyeva ${ }^{3}$, Alexandre Dolgui ${ }^{4}$, Ferry Jie $^{5}$ \\ ${ }^{I}$ Berlin School of Economics and Law, Department of Business Administration \\ Chair of International Supply Chain Management, 10825 Berlin, Germany \\ Phone: +493085789155;E-Mail:divanov@hwr-berlin.de \\ ${ }^{2}$ St. Petersburg Institute for Informatics and Automation of the RAS (SPIIRAS) \\ V.O. 14 line, 39199178 St. Petersburg, Russia; E-Mail: sokol@iias.spb.su \\ ${ }^{3} 2$ Ecole Nationale Supérieure des Mines de Nantes \\ IRCCYN, UMR CNRS 6597 La Chantrerie \\ 4, rue Alfred Kastler - B.P. 20722, F-44307 NANTES Cedex 3, France \\ E-mail: alexandre.dolgui@mines-nantes.fr \\ ${ }^{4}$ St.-Petersburg State University, Faculty of Applied Mathematics and Control Processes; \\ E-Mail: inna.solovyeva@gmail.com \\ ${ }^{5}$ School of Business IT and Logistics, RMIT University, Melbourne, \\ Australia; E-Mail:ferry.jie@rmit.edu.au \\ ${ }^{6}$ University ITMO, 199101 Saint Petersburg, Russia
}

\begin{abstract}
We consider time critical supply chains in the Australia dairy industry and recovery policies in the presence of the ripple effect. Ripple effect is the impact of a disruption on supply chain economic performance and disruption-based scope of changes needed in the supply structures and parameters to preserve the resilience. First, we describe the ripple effect in general and one example of the ripple effect in the dairy supply chain in Australia. Second, we present a model for reactive recovery policies in the dairy supply chain under conditions of the ripple effect and exemplify them on a simulation example. The results of this study can be used in future for comparing proactive and reactive approaches to tackling the ripple effect from resilience and flexibility views.
\end{abstract}

Keywords: dairy supply chain; ripple effect; resilience; adaptation; program control; positional optimization

This is an extended version of the conference paper

Dmitry Ivanov, Boris Sokolov, Inna Solovyeva, Alexandre Dolgui, Ferry Jie (2015). Ripple Effect in the Time-Critical Food Supply Chains and Recovery Policies, IFAC-PapersOnLine

Volume 48, Issue 3, 15th IFAC Symposium on Information Control Problems in Manufacturing INCOM 2015, Edited by Alexandre Dolgui, Jurek Sasiadek and Marek Zaremba, pp. 1682-1687. 


\section{Introduction}

Decision-making in the case of disruptions is one of the main challenges in the supply chain (SC) operations and is closely related to designing robust and controllable networks (Schwartz et al. 2006, Ivanov et al. 2010, Wahdani et al. 2011, Peng et al. 2011, Garcia et al. 2012, Baghalian et al. 2013). In particular, this challenge is faced in the ripple effect.

Ripple effect is the impact of a disruption on SC performance and disruption-based scope of changes in the SC structures and parameters (Ivanov et al. 2014). Following a disruption, its effect ripples through the SC. The scope of the rippling and its impact on economic performance depends both on robustness reserves (e.g., redundancies like inventory or capacity buffers) and speed and scale of recovery measures (Hendricks and Singhal, 2005; Sheffi and Rice, 2005; Tomlin, 2006; Klibi et al. 2010, Bode et al., 2011; Ivanov and Sokolov, 2013; Kim and Tomlin, 2013).

Disruptions are hardly predictable. Therefore, their risk and SC resilience should be estimated at the design and planning stages (Bakhsi and Kleindorfer, 2009; Blackhurst et al., 2011). At the control stage, contingency plans (e.g., alternative suppliers or shipping routes) must happen quickly to expedite stabilization and recovery in order to ensure continuity of supply and avoid long-term impact. In implementing such recovery policies, companies need a tool supported by collaboration and SC visibility solutions for assessing the impact of disruption on the SC as well as the effects from redirecting material flows (Knemeyer et al. 2009, Hishamuddin et al., 2013).

Although a lot of research has been conducted in the area of SC resilience on the prediction stage, there is still a gap in research regarding the recovery policies. In addition, so called time-critical SCs, e.g., the SCs with highly perishable products have got only limited attention from the research community rather than electronics or automotive SCs. The analysis of the time-critical SCs requires application of dynamic methods and can be performed with the help of optimal control models.

In this study, we consider the ripple effect in the Australian dairy SC and recovery policies on the basis of dynamic control models. Due to high likelihood of different natural disruptions in Australia, many Australia dairy SCs can be considered as time-critical systems. This paper consists of two parts. The first part describes the ripple effect in general and one example of the ripple effect in the Australia dairy supply chain. The second part presents a model for reactive recovery policies in the dairy supply chain under conditions of the ripple effect and exemplifies them on a simulation example in the dairy SC under conditions of the ripple effect. The paper is concluded by managerial insights and identifying future research avenues. 


\section{Literature Review}

Recovery policies may include different elements such as back-up suppliers and inventory re-placements (Ivanov et al. 2015, 2016). Since the focus of this study is on dynamic disruption and recovery analysis, we restrict ourselves to simulation and control approaches in this Section. Simulation approaches have been proved to be a suitable tool for analysis of SCD in terms of the ripple effect. Schmitt and Singh (2012) presented a quantitative estimation of the disruption risk at production and supply capacities in a multi-echelon SC using discrete-event simulation. They also consider dual sourcing as a contingency measure. The disruption risk is measured by "weeks of recovery" as the amplification of the disruption. Carvalho et al. (2012) analysed impacts of transportation disruptions on lead-time and overall costs in an automotive SC using ARENA-based simulation model.

Unnikrishnan and Figliozzi (2011) developed a scenario-based model with an adaptive routing policy. Vahdani et al. (2011) applied fuzzy program evaluation and review technique to calculate the completion time of SC operations in the case of a severe disruption. Xu et al. (2014) used AnyLogic software and modelled SC as an agent system to study the disruption at suppliers and recovery policies on the SC service level.

Ivanov et al. (2013) included transportation reconfiguration in the case of SC disruptions into the SCD in a multi-period model based on a combination of LP and optimal control. Ivanov et al. (2014b) developed a model for multi-period and multi-commodity SCD with structure dynamics considerations. The original idea of these studies is SC description as a non-stationary dynamic control system along with a linear programming model. In contrast to MIP formulation, they distribute static and dynamic parameters between the LP and control models. Xu et al. (2014) developed an approach to predict SC resilience by including recovery measures that use the analogy to biological cells with the abilities to self-adaptation and self-recovery. Paul et al. (2014) analysed series of disruptions over time and presented an inventory control-based model to develop optimal recovery policies for real time disruption management for a twostage batch production-inventory system with reliability considerations. They consider multiple disruptions and cases where new disruption may or may not affect the recovery plan of earlier disruptions.

It can be observed that reaction to disruptive events can be performed depending on the severity of disruptions as

- Parametrical adaptation or

- Structure adaptation

Parametrical adaptation represents the simplest case where stabilization and recovery are possible through tuning of some critical parameters like lead-time or inventory. Structure adaptation considers back-up supplier on contingency transportation plans. MIP formulations with facility fortification consider product 
shift to back-up suppliers if primary suppliers are disrupted. Inventory control models also suggest policies for recovery. Simulation techniques consider "what-if" scenarios which can be used by SC managers in the case of disruption occurrence to quickly estimate the recovery policies and impacts on operational and financial performance.

Summarizing, investment in SC protection can help to avoid many problems with disruptive events. However, it is impossible to avoid disruption completely. Simchi-Levi et al. (2014) underline that focus should be directed to the recovery policies regardless of what caused the disruption. Therefore, adaptation is needed to change SC plans, schedules or inventory policies in order to achieve the desired output performance. In this setting, SCs can be robust and stable only on the basis of decisions that are taken by people (unlike a pendulum, which returns to the stable state due to natural laws, without adaptation). In SCs, the adaptation (and more precisely, human-driven coordinated adaptation) is the precondition of stability and robustness (Ivanov and Sokolov, 2013).

Management science and operations research along with system dynamics and control theory contain a number of useful methods that can be used for analysis and for mitigating the ripple effect. Different methods are suited to different problems. No single technique is likely to prove a panacea in this field. While mathematical and stochastic optimization has its place at the SC design and planning stages without recovery considerations, they fail to throw much light on the dynamic behaviour of the SC. The implications of strategic SC design and tactical plans on SC performance at the execution and recovery stage can be enhanced by using models based on the dynamics of the execution processes.

\section{CASE STUDY AND METHODOLOGY}

\subsection{Time-critical dairy supply chains in Australia}

Dairy is the third largest agricultural industry in Australia, with a gross value of production of more than $\$ 4.6$ billion. The Australian Dairy Industry is a large industry in need of sustained expansion of its international markets. This industry generates exports of almost $\$ 3$ billion per year. While the domestic market offers only limited potential for expansion, there exist several good prospects for international market expansion. More than $60 \%$ of output is currently exported, mainly to Japan, Singapore, Malaysia, Indonesia and China. In terms of dairy production, the Australian dairy farmers produce around 9 billion litres of milk per year (36\% is used for cheese production, $24 \%$ for skim milk, powder and butter; $24 \%$ for fresh milk; and 12\% for whole milk powder (Department of Primary Industries 2010). While Australia contributes just $2 \%$ of world milk production, it accounts for around $10 \%$ of world dairy trade, ranking third behind New Zealand and the European Union. Over $60 \%$ of annual milk production is exported, mainly to Japan, Singapore, Malaysia, Indonesia and China. 
There are more than 8,000 dairy farms in Australia, which employ 21,500 people directly on-farm and almost 40,000 people industry-wide. Dairy manufacturing is a significant contributor to regional economies with annual sales valued at over $\$ 12$ billion a year. To date, the dairy industry principle focus has been on technological innovation. Dairy is the most developed of the major agricultural industries in terms of the value added and therefore emphasizes the significance, challenges and opportunities of effective and innovation practices in supply chain management. Dairy sector is undergoing rapid change because of globalisation, emerging markets and the availability of new technologies and business practices, a highly competitive market (local and export), fluctuations in markets and productivity growth, the trend toward more outsourcing of activities, and the rapid development of IT. In addition, dairy farmers face challenges arising from declining productivity growth and increasing competition from overseas producers. In particular, declining productivity growth, especially when compared with some international competitors, represents one of the most significant challenges for the dairy industry.

Dairy supply chain structure can be seen in Figure 1:

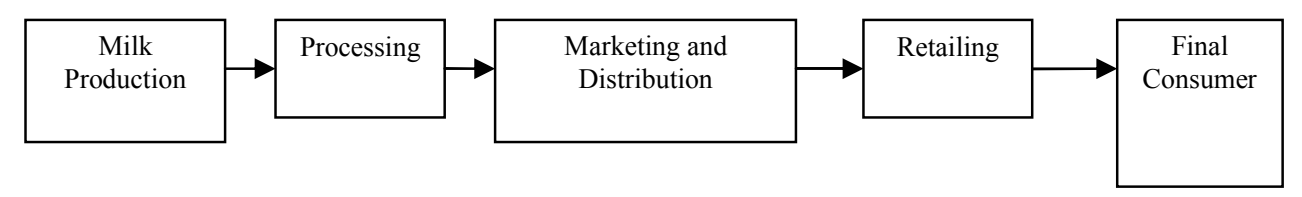

Figure 1. Dairy supply chain structure (Issar 2004)

Australian experiences a range of natural disasters including bushfires, floods, severe storms and cyclone Yasi. In October 2013, a series of bushfires occurred across the state of New South Wales. At the peak of the fires, on 18 October 2013, over 100 fires were burning across the state. The Queensland floods were followed by the 2011 Victorian floods which saw more than fifty communities in western and central Victoria also grapple with significant flooding. Severe Tropical Cyclone Yasi was a tropical cyclone that crossed the coast in northern Queensland, in the early hours of Thursday, 3 February 2011. Yasi originated from a tropical low near Fiji, intensified to a Category 3 cyclone on 31 January 2011 before the cyclone intensified to a Category 5 system. The cyclone's impact had been severe in some dairy regions.

The Australian dairy industry is working across the supply chain to mitigate the effects of extreme natural disasters. Transportation and particularly road access is essential to ensure dairy products (milk, yoghurt, cheese etc) can be moved from farm to factory and then for the final products to be supplied to wholesalers or retailers and on to the final consumer. 


\subsection{Methodology}

Two fundamental approaches to hedging time-critical dairy SC against the negative impacts of different disruptions - proactive and reactive can be proposed. Reactive approach aims at adjusting SC processes and structure in the presence of unexpected events. Proactive approach creates certain protection and takes into account possible perturbations while generating SC structures and execution plans.

The basis of the proposed methodology is control theoretic description of SCs as controllable dynamic systems with structure dynamics (Ivanov et al. 2010, Ivanov and Sokolov 2012a). This study is based on the scheduling SC model and algorithm in terms of optimal program control (OPC) (Ivanov and Sokolov $2012 \mathrm{~b})$. It is assumed in this study that a certain initial state $\mathbf{x}\left(T_{0}\right)$ is known and a schedule $\mathbf{u}(t)$ has been calculated. The developed SC schedule execution problem can be formulated: this is necessary to find a feasible control $\mathbf{u}(t),\left(t_{l}, t_{f}\right]$, that ensures the dynamic control model meets the constraint functions, and guides the dynamic system (i.e., the SC) $\dot{\mathbf{x}}=\varphi(t, \mathbf{x}, \mathbf{u})$ from the initial state to the specified final state subject to given end conditions. If there are several feasible controls (schedules), then the best one (optimal) should be selected in order to maximize (minimize) a general performance indicator $J_{G}$ taking into account priority coefficients $\lambda$ of key performance indicators $J_{1} \ldots J_{\mathrm{k}}$ (e.g., service level and costs):

$J_{\mathrm{G}}=\sum_{k=1}^{K} \lambda_{k} J_{k} ; \lambda_{k}=0 ; \sum_{k=1}^{K} \lambda_{k}=1$

In terms of OPC, the optimal program control of execution is at the same time the optimal SC schedule.

Based on the above-mentioned model and after describing SC planning stage in control terms, it becomes possible to analyse robustness as time functions and elaborate adaptation strategies. This is the goal of this paper. Robustness has to ensure for any time-invariant bounded uncertainties, SC is able to realize the performance of production and transportation execution and reject the disturbances. In the latter case, adaptation strategies have to be applied to recover the SC behaviour.

For experimental part, software AnyLogistix ${ }^{\circledR}$ has been used that is software for supply chain network design, analysis, and optimization. Simulation modeling methods allow us considering the details and specific traits of the SC elements. This allows not only visualizing network operations but also tracing every process inside. In addition, using simulation allows us to observe the impact of different disruptions and recovery policies in time and consider gradual capacity degradation and recovery. 


\section{REACTIVE RECOVERY WITH THE HELP OF OPTIMAL PROGRAM CONTROL VS PROGRAM-POSITIONAL OPTIMIZATION}

In accordance to different severity of disturbances, robustness and adaptation can be brought into correspondence to each other in order timely to derive necessary adaptation measures according to different deviations. Figure 1 depicts various variants of system behaviour changing in case of perturbation impacts to the system state $S_{l}{ }^{(u)}$ of the initial $\mathbf{u}(\mathrm{t})$.

The perturbation impacts cause various execution parameters' deviations $\Delta p_{i}$ and operability decrease in relation to the SC goals $\mathbf{J}=\left\{J_{1 \ldots \ldots}, J_{c}\right\}$. To match the robustness analysis and recovering the SC operability, we bring certain adaptation levels in correspondence to different deviations (Fig. 2).

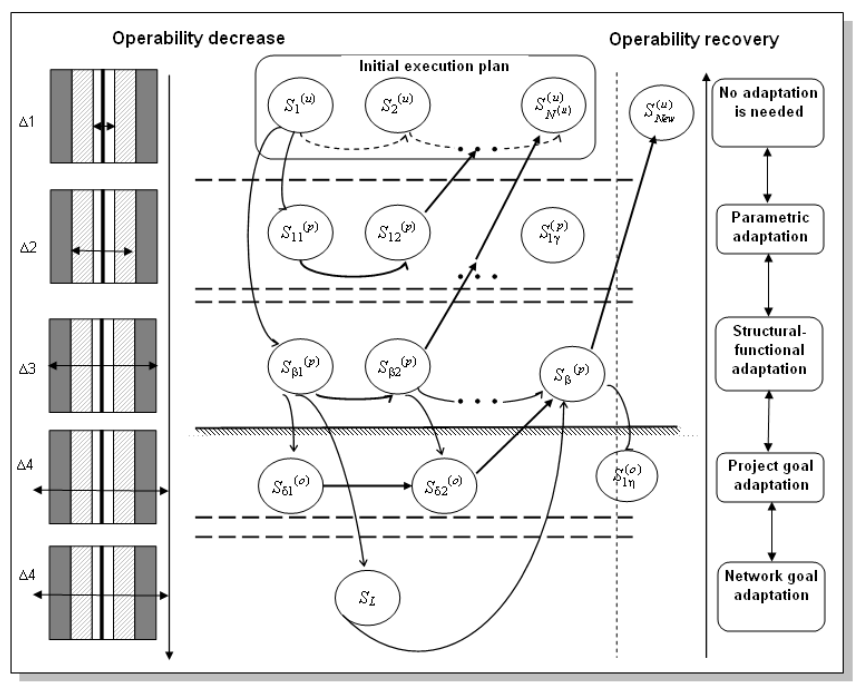

Figure 2. Dynamics of the SC execution (Ivanov and Sokolov 2010)

Each recovery level characterizes a certain control loop in relation to deviations and corresponds to certain management actions. We distinguish parametric adaptation (i.e., rush orders), structural-functional adaptation (i.e., supplier structure changing), project goals adaptation (i.e.., delivery delay), SC goals adaptation (i.e.., network profit changing) as well as SC strategy and models adaptation. Operative decision making about SC reconfiguration and adjustment is based both on the planning and execution information (selection of adaptation level in case of certain parameter deviations is related to the robustness analysis). In case of deviations (both in future - a preventive adaptation, and during a current operation running - a reactive adaptation), a decision maker can timely take necessary steps for the SC adjustment.

Two control principles can be used: OPC and positional control (with a closed feedback loop). The adaptation by OPC has been considered in the study (Ivanov and Sokolov 2012a). Program control is simpler to compute and implement, while positional (feedback) control performs better in the presence of persistent disturbances. Additional possibility to address the adaptation issues is model predictive control (MPC) that has been recently applied to SC domain (Perea et al. 2000). MPC is out of scope of this study. 
In hybrid strategies (Balashevich et al. 1994), at fixed instants the controller constructs feedback controls in response to the current system state, while in the intervals between these instants the controller uses programmed controls that correspond to the system state at the beginning of the interval. Such class of hybrid controls is quite natural for cases when the control law can be updated only at discrete time instants in the process of system operation, in particular where 1) the system state is measured continuously; 2) the state is measured only at discrete times. This is the case in SCs. That is why for further investigations into SC plan corrections combined program-positional control approach will be applied.

Let us assume that an optimal program for SC schedule execution control $\mathbf{u}(t)$ has been calculated (Ivanov and Sokolov 2012a). This scheduling model in terms of OPC may be represented in the following form (Eq. 3):

$$
M=\left\{\begin{array}{l}
\mathbf{u}(t) \mid \dot{\mathbf{x}}=\mathbf{f}(\mathbf{x}, \mathbf{u}, t) \\
\mathbf{h}_{0}\left(\mathbf{x}\left(t_{0}\right)\right) \leq 0, \mathbf{h}_{1}\left(\mathbf{x}\left(t_{f}\right)\right) \leq 0 \\
\mathbf{q}^{(1)}(\mathbf{x}, \mathbf{u})=0, \mathbf{q}^{(2)}(\mathbf{x}, \mathbf{u}) \leq 0
\end{array}\right.
$$

where $\mathbf{h}_{0}, \mathbf{h}_{1}$ are given functions of end conditions at time $t=t_{0}, t=t_{f}$ and $\mathbf{q}^{(1)}, \mathbf{q}^{(2)}$ is the generalized notation of the linear and non-linear constraints respectively (Ivanov and Sokolov 2010). In order to determine the optimal adaptation program, the positional optimization method can be used. It is to decide on the best adaptation programs regarding the attainability of key performance indicators from the set $\mathbf{J}$. For example, it may be necessary to compare the immediate adaptation program (i.e., the immediate recovery and return on the planned execution) or smooth adaptation program (i.e., constructing an alternative execution in anticipating new perturbations). Such analysis also involves adaptation costs which may vary in different strategies.

The following assumptions are made. Let us define planned execution program as $u_{p r}(t), x_{p r}(t)$. Perturbations (2) are assumed to be piecewise continuous functions. Information about current state $\widetilde{x}(t)$ of the system in the model (3) is available at time points $t_{\sigma} \in\left[t_{0}, t_{f}\right.$ ) as the state vector $\mathbf{x}_{\sigma}$. The problem of plan correction consists of finding control $\mathbf{u}_{k}(t)$ during the execution of control $u_{p r}(t)$ within the interval $\left[t_{0,} t_{f}\right)$ so that the perturbation impacts are compensated and the objective function (4) is minimized:

$\widehat{J}=\int_{t_{0}}^{t_{f}}\left|\mathbf{x}(t)-\mathbf{x}_{p r}(t)\right| d t \rightarrow \min$ 
Denote $\vec{y}(t)=\overrightarrow{\widetilde{x}}(t)-\vec{x}_{p r}(t)$ as deviation vector and $\mathbf{w}(t)$ as correcting control vector that can be found from $\mathbf{u}_{k}(t)=\mathbf{u}(t)+\mathbf{w}(t)$. The found control $\mathbf{u}_{k}(t)$ can be now used in the model (1). The constraints have now the form $\left.\mathbf{q}^{(1)}\left(\mathbf{y}, \mathbf{u}_{k}\right)=0, \mathbf{q}^{(2)}\left(\mathbf{y}, \mathbf{u}_{k}\right) \leq 0\right\}$.

This transforms the model (1) to the new model $\tilde{M}$. As proved in Ivanov and Sokolov (2012b), the model $\tilde{M}$, as the model $M$, is a linear finite-dimensional non-stationary dynamic system.

Consider the time horizon for which the scheduling problem has be solved $\left[t_{0}, t_{f}\right), t_{0}<t_{f}<+\infty$. Consider discretization step $h=\left(t_{f}-t_{0}\right) / L$, where $L$ is a large number. Define $w(t), t \in\left[t_{0}, t_{f}\right)$ as discrete control $\mathbf{w}(t)=w\left(t_{0}+l h\right)$ for $t \in\left[t_{0}+l h, t_{0}+(l+1) h\right), l=\overline{0, L-1}$. In this class of discrete control, the control $w(t)$ will be searched for with the help of positional optimization.

Consider at time $\tau=t_{\sigma}$ the OPC problem for $\tilde{M}$. Denote $\mathbf{w}(\tau \mid \tau, z)$ as optimal program control for position $(\tau, z)$; this is also optimal control of the auxiliary problem. Denote $Y(\tau)$ as a set of all possible initial states of $\mathbf{z}=\mathbf{y}(\tau)$ for which the problem has a solution for fixed $\tau, \mathbf{z}=\mathbf{y}(\tau), \mathbf{y}(\tau) \in Y(\tau), t \in T(\tau)=\left[\tau, t_{f}\right)$ as proved in the study by Gabasov et al. (2005).

Taking into account particular features of the problem $\tilde{M}$ (non-stationarity, interval linear constraints on control $\mathbf{w}(t)$, simultaneous optimization of assignment and flow distribution control), the method of numerical optimization of time-dependent multidimensional systems under polyhedral constraints can be used (Gabasov et al. 2005). The choice of this method is based on the specific form of constraints and independency from the discretization step $h$.

End conditions and performance indicator in the auxiliary problem can be expressed as $\mathbf{y}(\tau)=\mathbf{y}_{\tau}, y\left(t_{f}\right)=0$, and $\widehat{J}_{\tau}(z)=\min \int_{\tau}^{t_{f}}|\mathbf{y}(t)| d t$. Determine $\mathbf{w}(t)$ consecutively in solving at each point of time $\tau=t_{\sigma}$ the auxiliary problem with new initial conditions $\mathbf{y}\left(\tau=t_{\sigma}\right)=\mathbf{y}_{\sigma}$.

From the technical point of view, the auxiliary problems belong to the OPC problem class with interval constraints. In the study (Gabasov et al. 2001) has been shown that they may be transformed in the case of discrete control to linear programming (LP) problems with the band structure matrix which can be solved with adaptive methods. 


\section{GENERALIZED ALGORITHM}

At the first stage, the basic model (1) is applied to find the OPC $u_{p r}(t), x_{p r}(t)$. At the second stage, AS method is applied to analyse SC robustness. The result of this analysis is the upper and low bounds of the tolerance area (compare with Figure 1) for $u_{p r}(t), x_{p r}(t)$ execution. In remaining within these bounds, SCs is guaranteed to execute performance and reject disturbances subject to the considered risk level. Finally, at the third stage SC execution has to be adapted in the case of disturbances.

Let us summarize the algorithm of program-positional SC control for the stage 3:

Step 1. Transformation of the model $M$ to the model $\tilde{M}$.

Step 2. Generation of the deviation system, new constraint system, and goal function.

Step 3. Formation of the auxiliary problem of OPC with initial conditions $\left(t_{\sigma}, \mathbf{x}_{\sigma}\right)$.

Step 4. Realisation of the synthesis procedure in the discrete control class $\mathbf{w}(t)=w\left(t_{0}+l h\right)$ for $t \in\left[t_{0}+l h, t_{0}+(l+1) h\right), l=\overline{0, L-1}$.

Step 5. Transformation of the auxiliary OPC problem to LP problem.

Step 6. Solution of the LP problem with the help of adaptive method on the set $T(\tau)=\left[\tau, t_{f}\right)$.

Step 7. Implementation of the correcting control within the interval prior to the next information update point $\left(t_{\sigma+1}, \mathbf{x}_{\sigma+1}\right)$.

Components of the multi-objective vector $\mathbf{J}=\left\{J_{1 \ldots \ldots}, J_{c}\right\}$ for attainable sets can be selected according to the results of analysis made in (Jie et al. 2012) as follows: $\mathbf{J}=\left\{J_{1}:\right.$ costs; J2:service level; $J_{3}:$ quality; $J_{4}$ :delivery time $\}$. Fig. 2 can be used as a basis for the development of control programs $u_{p r}(t), x_{p r}(t)$ and recovery policies $\mathbf{w}(t)=w\left(t_{0}+l h\right)$. Experimental results are currently under development.

\section{SIMULATION EXAMPLE}

The simulation has been performed in AnyLogistix ${ }^{\circledR}$ on a standard desktop computer. The simulation experiments have been done in regard to the following scenarios:

- Operating the $\mathrm{SC}$ with no disruptions

- Operating the SC without DCs in VIC and NSW

- Operating the SC without DCs in VIC and NSW with the use of a back-up DC near Melbourne and Sydney ports and using multiple sourcing 
- Operating the SC without DCs in VIC and NSW using expensive emergency transportation means.

In each scenario, we are interested to compute:

- DCs's revenues, costs and profits

- Revenue at customers

- Inventory dynamics at DCs

The analysis of the revenues, costs, and profits along with the inventory dynamics analysis may help us to identify the performance impacts of disruptions in regard to different recovery (contingency) policies in order to support the decision-making on selection of recovery policies in the SC.

\subsection{Operating the SC with no disruptions}

Consider a fragment of a diary SC in Australia that comprises three suppliers, five distribution centers (DC) and 24 customers (Fig. 2).

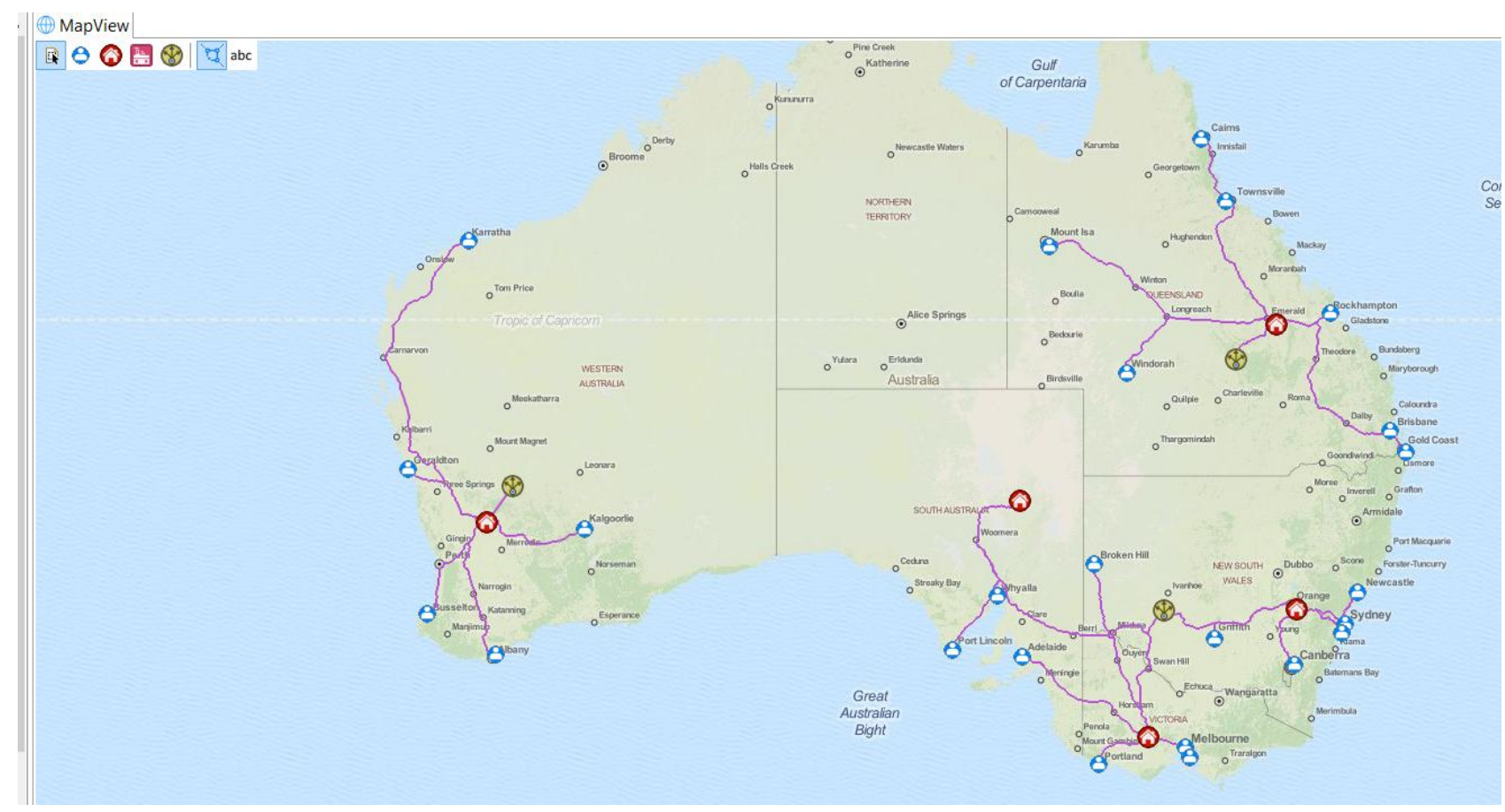

Fig. 3. Australian Diary Supply Chain

The SC employs the regional and single sourcing policy. Five DCs are located in Western Australia (WA), South Australia (SA), Victoria (VIC), Queensland (QLD), and New South Wales (NSW). The normally distributed demands with a mean $q$ at customers are given at a daily basis $t=1$ as shown in Table 1.

Table 1 Demand data 


\begin{tabular}{|l|l|}
\hline Customer & Daily Demand \\
\hline Adelaide & 125 \\
\hline Albany & 150 \\
\hline Kalgoorlie & 150 \\
\hline Geraldton & 150 \\
\hline Portland & 155 \\
\hline Calms & 255 \\
\hline Brisbane & 255 \\
\hline Canberra & 255 \\
\hline Karratha & 150 \\
\hline Windorah & 255 \\
\hline Townsville & 255 \\
\hline Mount Isa & 255 \\
\hline Melbourne & 555 \\
\hline Whyalla & 125 \\
\hline Broken Hill & 255 \\
\hline Port Lincoln & 125 \\
\hline Newcastle & 255 \\
\hline Gold Coast & 255 \\
\hline Busselton & 155 \\
\hline Bockhampton & 255 \\
\hline Sydney & 455 \\
\hline Griffith & 255 \\
\hline Export 1 / Port Sydney & 2,000 \\
\hline Export 2 / Port Melbourne & 2,500 \\
\hline
\end{tabular}

It can be observed that along with 22 national customers, there are two international customers with very high demand that are defined as „Export 1“ and „Export 2“ and located close to the international ports in Melbourne (VIC) and Sydney (NSW). Since export of diary product is very important for Australia, demand satisfaction at these customers is of high importance.

Further we are given inventory control policies at DCs as shown in Table 2.

Table 2. Inventory control policies at DCs

\begin{tabular}{|l|l|l|}
\hline Facility & $s$ (re-order point) & $S$ (target inventory) \\
\hline DC SA & 800 & 1,200 \\
\hline DC WA & 800 & 1,200 \\
\hline DC VIC & 2,800 & 5,000 \\
\hline DC QLD & 1,300 & 2,000 \\
\hline DC NSW & 4,000 & 6,000 \\
\hline
\end{tabular}


For experiments, we assume $(\mathrm{s}, \mathrm{S})$ inventory control policies without initial stock. Selling price is set at $\$ 3$ per litre and costs is set of $\$ 1$ per litre. Transportation costs equals $\$ 0.001 \mathrm{x}$ distance $\mathrm{x}$ shipment quantity. Transportation capacity is considered to be sufficient and allows LTL shipments.

The simulation results are shown in Fig. 4 and Table 3. 

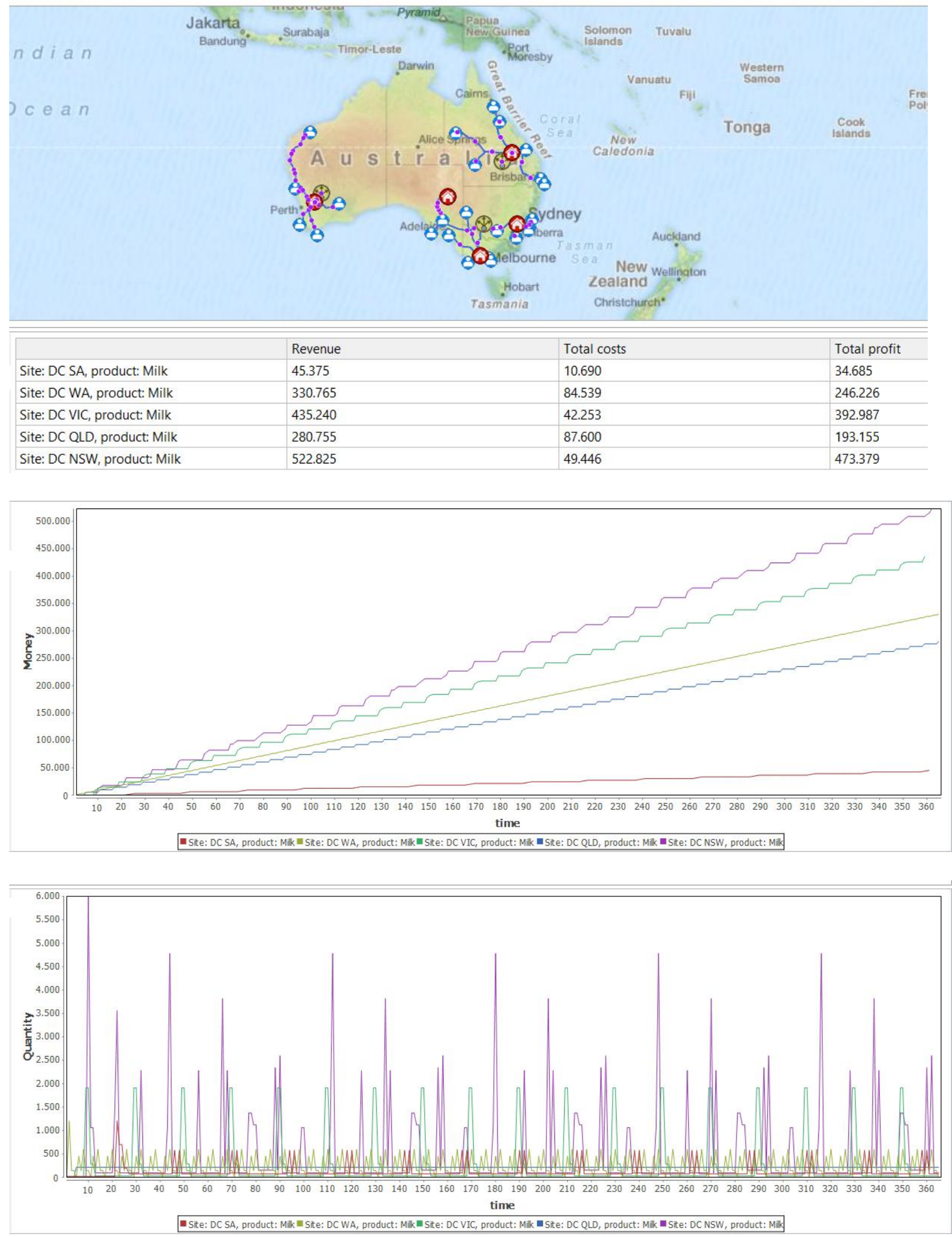

Fig. 4. DC performance and inventory dynamics when operating the SC without disruptions 
Table 3. Customer revenues when operating the SC without disruptions

\begin{tabular}{|l|l|}
\hline Customer & Revenue, $\mathbf{S}$ \\
\hline Adelaide & 26,625 \\
\hline Albany & 53,550 \\
\hline Kalgoorlie & 54,000 \\
\hline Geraldton & 80,100 \\
\hline Portland & 33,480 \\
\hline Calms & 44,370 \\
\hline Brisbane & 44,370 \\
\hline Canberra & 62,730 \\
\hline Karratha & 76,050 \\
\hline Windorah & 44,370 \\
\hline Townsville & 45,135 \\
\hline Mount Isa & 43,605 \\
\hline Melbourne & 89,910 \\
\hline Whyalla & 21,000 \\
\hline Broken Hill & 68,085 \\
\hline Port Lincoln & 21,375 \\
\hline Newcastle & 70,380 \\
\hline Gold Coast & 44,370 \\
\hline Busselton & 55,335 \\
\hline Bockhampton & 765 \\
\hline Sydney & 128,310 \\
\hline Griffith & 55,845 \\
\hline Export 1 / Port Sydney & 216,000 \\
\hline Export 2 / Port Melbourne & 195,000 \\
\hline & \\
\hline
\end{tabular}

It can be observed from Fig. 4 and Table 3 that operating the SC without disruptions allows achieving total revenue at customers of $\$ 2,077.373$, total revenue at DCs of $\$ 1,614.960$ and total profit at DCs of $\$ 1,340.432$.

\subsection{Operating the SC without DCs in VIC and NSW}

In this scenario, two DCs (VIC and NSW) are not available. The simulation results subject to the parameters from $\S 6.1$ are depicted in Fig. 5 and Table 4. 
Simulation: Simulation12

Pause

x1 Stop Show tables Scenario: Copy of Copy of Australia11

22.01.2016 11:09:21

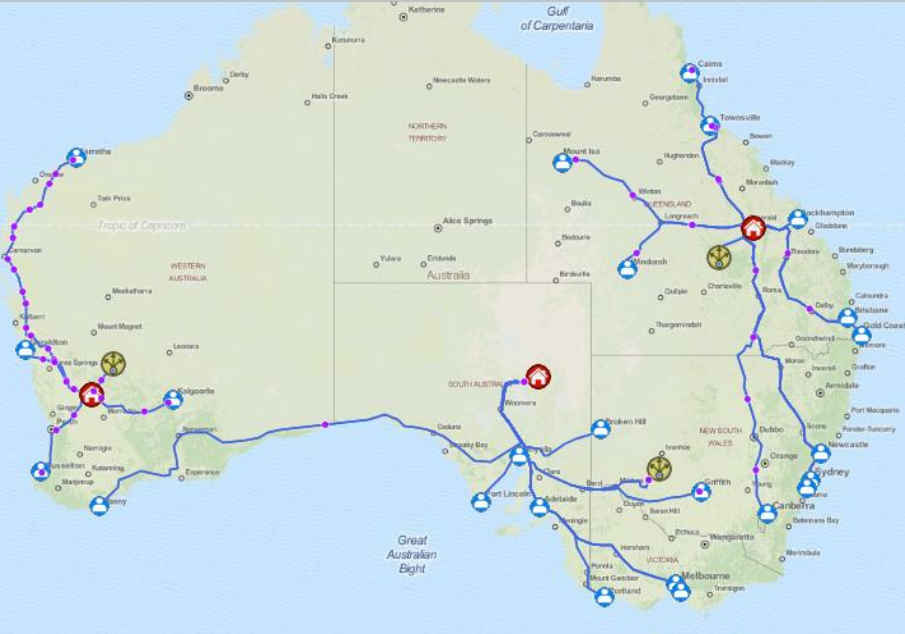

\begin{tabular}{|l|l|l|l|}
\hline & Revenue & Total costs & Total profit \\
\hline Site: DC SA, product: Milk & 49.245 & 23.054 & 26.191 \\
\hline Site: DC WA, product: Milk & 330.315 & 90.473 & 239.842 \\
\hline Site: DC QLD, product: Milk & 280.755 & 97.760 & 182.995 \\
\hline
\end{tabular}

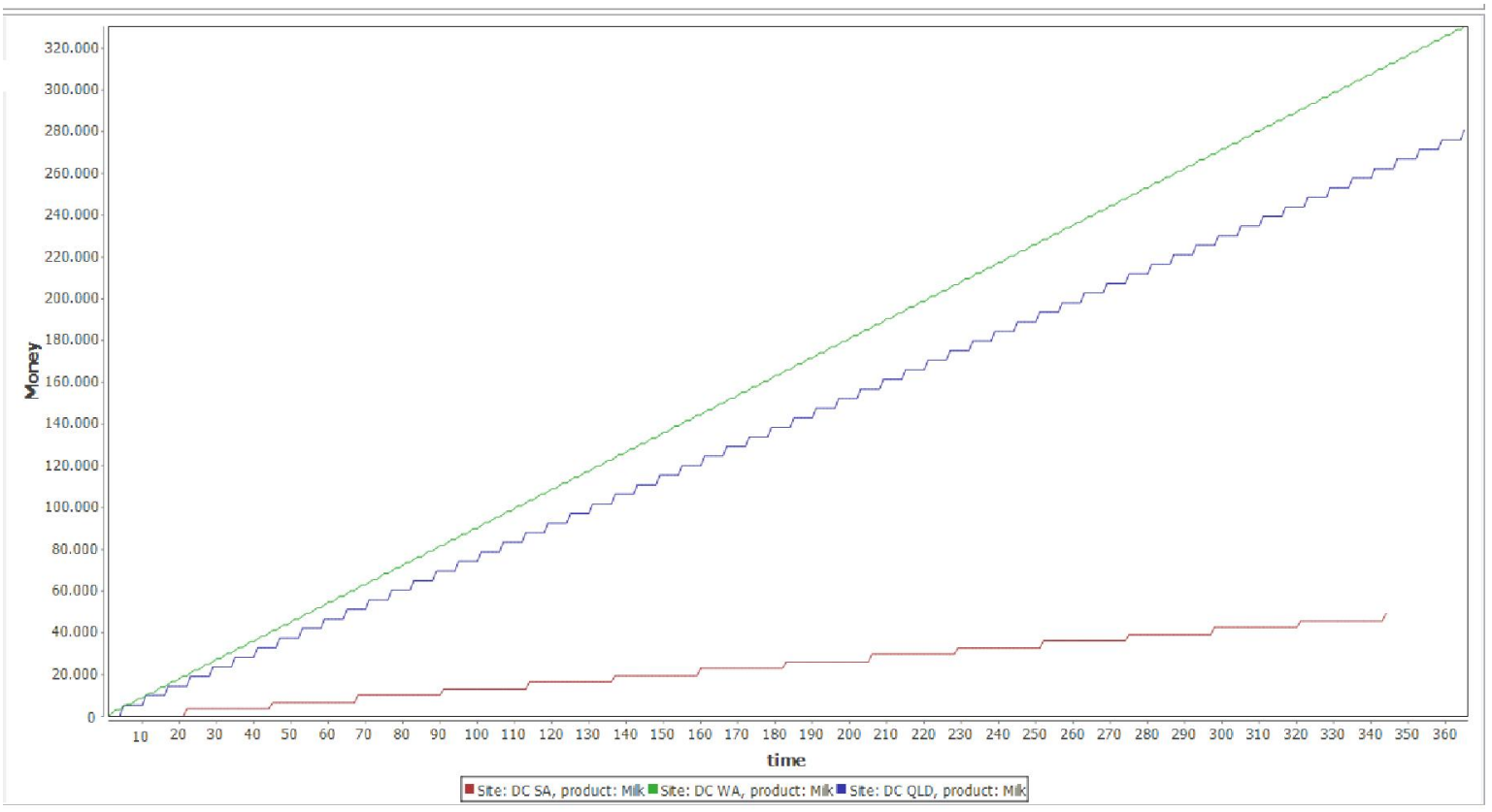

Fig. 5. DC performance when operating the SC without DCs in VIC and NSW

Table 4. Customer revenues when operating the SC without DCs in VIC and NSW

\begin{tabular}{|l|l|l|}
\hline Customer & Disruption case, Revenue, \$ & Revenue, \$, if no disruption \\
\hline Adelaide & 5,625 & 26,625 \\
\hline Albany & 5,850 & 53,550 \\
\hline Kalgoorlie & 54,000 & 54,000 \\
\hline Geraldton & 107,100 & 80,100 \\
\hline Portland & 6,510 & 33,480 \\
\hline
\end{tabular}




\begin{tabular}{|l|l|l|}
\hline Calms & 44,370 & 44,370 \\
\hline Brisbane & 44,370 & 44,370 \\
\hline Canberra & 42,840 & 62,730 \\
\hline Karratha & 101,700 & 76,050 \\
\hline Windorah & 44,370 & 44,370 \\
\hline Townsville & 45,135 & 45,135 \\
\hline Mount Isa & 43,605 & 43,605 \\
\hline Melbourne & 11,655 & 89,910 \\
\hline Whyalla & 3,000 & 21,000 \\
\hline Broken Hill & 6,120 & 68,085 \\
\hline Port Lincoln & 3,000 & 21,375 \\
\hline Newcastle & 765 & 70,380 \\
\hline Gold Coast & 0 & 44,370 \\
\hline Busselton & 55,335 & 55,335 \\
\hline Bockhampton & 0 & 765 \\
\hline Sydney & 0 & 128,310 \\
\hline Griffith & 5,355 & 55,845 \\
\hline Export 1 Port Sydney & 0 & 216,000 \\
\hline Export 2 / Port Melbourne & 0 & 195,000 \\
\hline It Can be observed fiom & 1 & \\
\hline
\end{tabular}

It can be observed from Fig. 5 and Table 4 that the disruptions have significant performance impact. Operating the SC without DCs in VIC and NSW allows achieving total revenue at customers of \$630,705 (instead of $\$ 2,077.373$ without disruptions, i.e. a decrease in sales of 70\%), total revenue at DCs of $\$ 660,315$ (instead of $\$ 1,614.960$, i.e. a decrease of $60 \%$ ) and total profit at DCs of $\$ 449,028$ (instead of $\$ 1,340.432$, i.e. a decrease of $66 \%$ ). It can be further observed that both export customers with the highest revenues and demand cannot be served at all. A possible solution can be establishment of a back-up DC near Melbourne and Sydney ports. This scenario will be investigated in $\S 6.3$.

6.3 Operating the SC without DCs in VIC and NSW with the use of a back-up DC near Melbourne and Sydney ports and using multiple sourcing VIC, NSW, QLD and SA

This scenario implies a contingency plan in the form of a back-up DC (with the inventory policy s=1,200; $\mathrm{S}=6,000$ ) near Melbourne and Sydney ports and using multiple sourcing VIC, NSW, QLD and SA. The simulation results are shown in Fig. 6.

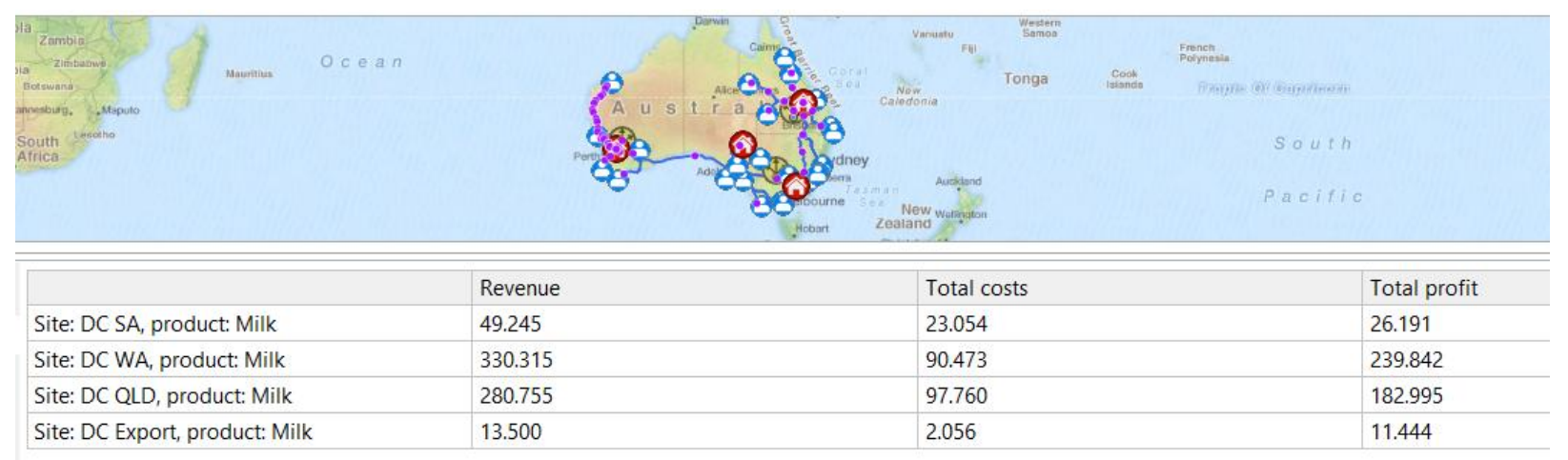


Fig. 6. DC performance when operating the SC without DCs in VIC and NSW with the use of a back-up DC near Melbourne and Sydney ports and using multiple sourcing VIC, NSW, QLD and SA

Fig. 6 illustrate the simulation results when operating the SC without DCs in VIC and NSW with the use of a back-up DC near Melbourne and Sydney ports and using multiple sourcing VIC, NSW, QLD and SA. This recovery policy allows achieving total revenue at customers of $\$ 644,505$ (instead of 630,705 without the back-up DC) and total revenue at DCs of $\$ 673,815$ (instead of $\$ 660,315$ without the back-up DC). It can be observed that only a small increase in revenues and sales can be achieved if using a backup DC. This can be explained by the fact that not only the DCs but also the suppliers (i.e., the farmers and processing plants) are disrupted in the case of natural catastrophes in some regions.

\subsection{Operating the SC without DCs in VIC and NSW using expensive emergency transportation means}

In this setting, we consider the scenario similar to $§ 2$ but also include more severity in the disruption so that normal transportation routes cannot be used and expensive emergency transportation means with costs of $\$ 0.01$ for $\mathrm{km} \mathrm{x}$ weight are used (instead of normal costs $0 \$ 0.01$ for $\mathrm{km} \mathrm{x}$ weight). In this case, total profit at all three DCs is decreased $(\mathrm{SA}=\$-205,552, \mathrm{WA}=\$-614,624, \mathrm{QLD}=\$-743,356)$.

\section{CONCLUSIONS}

In this study, time critical SCs in the Australia dairy industry and recovery policies in the presence of the ripple effect have been considered. Ripple effect is the impact of a disruption on SC economic performance and disruption-based scope of changes needed in the supply structures and parameters to preserve the resilience. A dynamic model for reactive recovery policies in the dairy SC under conditions of the ripple effect and exemplifies them on a simulation example.

From a practical point of view, the results of the research in this domain are to provide operations and SC planners with new tools in order to support them in decisions on how to

- $\quad$ estimate the impact of possible perturbations on economic performance at the SC design and inventory planning stage

- $\quad$ quickly estimate the impact of real plan deviations on economic performance at the execution stage

- $\quad$ suggest efficient and effective stabilization and recovery measures.

The results of this study can be used in future for comparing proactive and reactive approaches to tackling the ripple effect from resilience and flexibility views. We considered SC resilience as a dynamic property that emerges through controlled adaptability on the basis of feedback loops. The simulation experiments have been done in regard to the normal operation mode, operating with disruptions, and operating with 
disruptions and using recovery policies (contingency plans). In each scenario, we analysed performance impact of disruptions and recovery policies in regard to revenues, costs and profits.

For the considered example, we found out the performance impact of using a back-up DC and alternative transportation means. Such an analysis of the revenues, costs, and profits along with the inventory dynamics analysis may help the SC managers to identify the performance impacts of disruptions in regard to different recovery (contingency) policies in order to support the decision-making on employment of recovery policies in the SC.

In regard to the extension of this study, it is to mention that a crucial practical problem is to determine where exactly changes are needed: in the schedule, in the master plan or in the business plan. Such an analysis should incorporate multiple control loops including corresponding business-process models, quantitative models, and IT for gathering and processing real-time data. Decentralized interests of SC enterprises also have to be included in such analyses.

First, different control strategies regarding construction of the optimal recovery programs can be analysed. Here, basic cybernetic principles (critical events, final deviations, free trajectories and interim solutions) can be investigated. For example, an immediate adaptation program (i.e., immediate recovery and return on the planned execution) and smooth adaptation program (i.e., constructing an alternative execution in anticipation of new perturbations) can be compared. Second, different control objectives may be considered (e.g., maintaining planned economic performance, extremizing this performance through control, maintaining plan stability rather than recovering the planned economic performance, etc.).

Inventory and facility costs are not considered in this study since milk is a time critical product and DCs play the role of cross-docking points in the SC. In addition, costs of facility fortification need to be addressed in future along with creation of more complex cases with multiple products, inclusion factory and supplier capacities, and investigating impact of different inventory control policies.

In future, the focus of this research may be directed to computational analysis and comparison of different recovery policies with regard to some empirical data sets the collection of each is currently under development. In addition, elements of recovery should be considered integrated with proactive models. Such integration requires simultaneous consideration of both the static structural properties of SCD and execution dynamics subject to uncertainty and disruptions. The efficient application of model-based support for any quantitative analysis implies clear description of control processes in the case of different deviations and disturbances. Such processes (i.e., control loops) should also include different control objectives and strategies (e.g., recovering planned execution, maintaining plan stability, minimizing future impacts, etc.). 
In addition, impacts of control actions on economic performance and related costs of control have not so far found sufficient consideration in the literature.

\section{Funding}

The research described in this paper is partially supported by the Russian Foundation for Basic Research (grants 15-07-08391, 15-08-08459, 16-57-00172-Bel_a, 16-07-00779, 16-08-01068, 16-07-01277), by grant ITMO 074U01 supported by Government of Russian Federation, Program "5-100-2020", by Department of nanotechnologies and information technologies of the RAS (project 2.11), by Program NTS "Monitoring SG" (project 1.4.1-1), and by program 6.1 .1 of St. Petersburg Polytechnical University.

\section{REFERENCES}

Baghalian, A., Rezapour, S., and Farahani, R.Z. 2013. "Robust supply chain network design with service level against disruptions and demand uncertainties: A real-life case." European Journal of Operational Research 227 (1): 199-215.

Bakshi, N., and Kleindorfer, P.R. 2009. "Co-opetition and investment for supply-chain resilience." Production and Operations Management 18 (6): 583-603.

Balashevich, N. V., R. Gabasov, and F. M. Kirillova 1994. "Program-positional optimization of dynamic systems." Cybernetics and Systems Analysis 30 (1): 47-53.

Blackhurst, J., Dunn, K.S., and Craighead, C.W. 2011. "An empirically derived framework of global supply resiliency." Journal of Business Logistics 32 (4): 374-391.

Bode, C., Wagner, S.M., Petersen, K.J., and Ellram, L.M. 2011. "Understanding responses to supply chain disruptions: Insights from information processing and resource dependence perspectives." Academy of Management Journal 54 (4): 833-856.

Carvalho, H., Barroso, A.P., Machado, V.H., Azevedo, S., \& Cruz-Machado, V. (2012). Supply chain redesign for resilience using simulation. Computers \& Industrial Engineering, 62(1), 329-341.

Department of Primary Industries (2010). "DPI services to dairy farmers.” Department of Primary Industries Discussion (1): 1-54.

Gabasov R., Dmitruk N.M., and Kirillova F.M. 2005. "Numerical Optimization of Time-Dependent Multidimensional Systems under Polyhedral Constraints." Computational Mathematics and Mathematical Physics 45 (4): 593-612.

Gabasov R., Kirillova F.M., and Ruzhitskaya E.A. 2001. "Damping and Stabilization of a Pendulum with Large Initial Disturbance." Journal of Computer and Systems Sciences international 40 (1): 24-33.

Garcia, C.A., Ibeas, A., Herrera, J. and Vilanova, R. 2012. "Inventory control for the supplychain: An adaptive control approach based on the identification of the lead-time Omega", 40, 314-327 JOURNAL?

Hendricks, K. B., and Singhal, V. R. 2005. „Association between supply chain glitches and operating performance." Management Science 51 (5): 695-711.

Hishamuddin, H., Sarker, R.A., and Essam, D. 2013. "A recovery model for a two-echelon serial supply chain with consideration of transportation disruption." Computers and Industrial Engineering 64 (2): 552-561.

Issar, G. 2004. Strategies and Relationships in the Dairy-food Supply Chain: Options for Milk Producers in Southeast Queensland. Doctor of Philosophy, the University of Queensland.

Ivanov D., and Sokolov B. 2012a. "Structure dynamics control approach to supply chain planning and adaptation." International Journal of Production Research 50 (21): 6133-6149.

Ivanov D., and Sokolov B. 2013. "Control and system-theoretic identification of the supply chain dynamics domain for planning, analysis, and adaptation of performance under uncertainty." European Journal of Operational Research 224 (2): 313-323.

Ivanov D., Sokolov B., and Pavlov, A. 2013. "Dual problem formulation and its application to optimal re-design of an integrated production-distribution network with structure dynamics and ripple effect considerations." International Journal of Production Research 51 (18): 5386-5403.

Ivanov, D., and Sokolov, B. 2010. Adaptive Supply Chain Management. London: Springer

Ivanov, D., and Sokolov, B. 2012b. "Dynamic supply chain scheduling." Journal of Scheduling 15 (2): 201-216. 
Ivanov, D., Sokolov, B., and Dolgui, A. 2014a. "The Ripple effect in supply chains: trade-off "efficiencyflexibility-resilience' in disruption management." International Journal of Production Research, 52 (7): 21542172.

Ivanov, D., Sokolov, B., and Kaeschel J. 2010. "A multi-structural framework for adaptive supply chain planning and operations with structure dynamics considerations." European Journal of Operational Research 200: 409420

Ivanov, D., Sokolov, B., and Pavlov, A. 2014b. "Optimal distribution (re)planning in a centralized multi-stage network under conditions of ripple effect and structure dynamics." European Journal of Operational Research 237 (2): 758-770.

Ivanov D., Sokolov B., Pavlov A., Dolgui A., Pavlov D. (2016). Disruption-driven supply chain (re)-planning and performance impact assessment with consideration of pro-active and recovery policies. Transportation Research: Part E, 10.1016/j.tre.2015.12.007.

Ivanov, D., Hartl, R., Dolgui, A., Pavlov, A., Sokolov, B. (2015) Integration of aggregate distribution and dynamic transportation planning in a supply chain with capacity disruption and the Ripple effect consideration, International Journal of Production Research, 53:23, 6963-6979.

Jie, F. and Parton, K. 2009. "The need for improved skills in the Australian meat industry." International Review of Business Research Papers 5 (4): 257-269.

Jie, F., Parton, K.A. and Cox, R.J. 2012. "An agile supply chain analysis of Australian beef wholesalers and retailers." International Journal of Agile Systems and Management 5 (4): 297-318.

Kim, S.H., and Tomlin, B. 2013. "Guilt by Association: Strategic Failure Prevention and Recovery Capacity Investments." Management Science 59 (7): 1631-1649

Klibi, W., Martel, A., and Guitouni, A. 2010. "The design of robust value-creating supply chain networks: A critical review." European Journal of Operational Research 203 (2): 283-293.

Knemeyer, A.M., Zinn, W., and Eroglu, C. 2009. "Proactive planning for catastrophic events in supply chains." Journal of Operations Management 27 (2): 141-153.

Lee, E.B., and Markus, L. 1967. Foundations of optimal control theory. Wiley and Sons: New York.

Paul, S.K., Sarker, R., \& Essam, D. (2014). Real time disruption management for a two-stage batch productioninventory system with reliability considerations. European Journal of Operational Research, 237, 113-128.

Peng, P., Snyder, L. V., Lim, A., and Liu, Z. 2011. "Reliable logistics networks design with facility disruptions." Transportation Research Part B: Methodological 45 (8): 1190-1211.

Schmitt, A.J., \& Singh, M. (2012). A quantitative analysis of disruption risk in a multi-echelon supply chain. International Journal of Production Economics, 139 (1), 23-32.

Schwartz D, Wang W, and Rivera D. 2006. "Simulation-based optimization of process control policies for inventory management in supply chains." Automatica 125 (2):1311-20.

Sheffi, Y., and Rice, J.B. 2005. "A supply chain view of the resilient enterprise." MIT Sloan Management Review 47 (1): 41-48.

Simchi-Levi, D., Schmidt, W., \& Wei, Y. (2014). From superstorms to factory fires: Managing unpredictable supply chain disruptions. Havard Business Review, February.

Tomlin, B. 2006. "On the Value of Mitigation and Contingency Strategies for Managing Supply Chain Disruption Risks" Management Science 52: 639-657.

Unnikrishnan, A., \& Figliozzi, M. (2011). Online freight network assignment model with transportation disruptions and recourse. Transportation research record. Journal of the Transportation Research Board, 2224(1), 17-25.

Vahdani, B., Zandieh, M., \&Roshanaei, V.(2011). A hybrid multi-stage predictive model for supply chain network collapse recovery analysis: A practical framework for effective supply chain network continuity management. International Journal of Production Research, 49(7), 2035-2060.

Vahdani, B., Zandieh, M., and Roshanaei, V. 2011. "A hybrid multi-stage predictive model for supply chain network collapse recovery analysis: A practical framework for effective supply chain network continuity management." International Journal of Production Research 49 (7), 2035-2060.

Xu, M., Wang, X., \& Zhao, L. (2014). Predicted supply chain resilience based on structural evolution against random supply disruptions. International Journal of Systems Science: Operations \& Logistics, 1(2), 105-117. 